\title{
Low-frequency sea level variation and its correlation with climate events in the Pacific
}

\author{
JIN TaoYong ${ }^{1,2}$, LI JianCheng $^{1,2}$, JIANG WeiPing $^{1 *} \&$ CHU YongHai ${ }^{1,2}$ \\ ${ }^{1}$ School of Geodesy and Geomatics, Wuhan University, Wuhan 430079, China; \\ ${ }^{2}$ Key Laboratory of Geospace Environment and Geodesy, Ministry of Education, Wuhan 430079, China
}

Received December 22, 2011; accepted March 14, 2012; published online May 30, 2012

\begin{abstract}
Global mean sea level (GMSL) has not only significant secular trend and seasonal variations, but also inter-annual and decadal variations. This paper reconstructs the time series of GMSL variations between 1948 and 2007 by combining satellite altimeter measurements and tide gauge observations. Based on the time series, the acceleration of GMSL rise in the second half of 20th century is estimated to be $0.010 \pm 0.009 \mathrm{~mm} / \mathrm{a}^{2}$, and multi-scale low frequency sea level oscillations including decadal variations are detected, and the high-rate of GMSL rise during 1993-2003 is locate in the ascending phase of low frequency oscillation. Then, using the reconstructed GMSL time series after removing the secular trend from satellite altimetry and tide gauges measurements, it shows that low frequency signal of sea level variation has strong correlations with the index of El Niño/Southern Oscillation (ENSO) and Pacific Decadal Oscillation (PDO). But in several time periods, they have large difference due to effects of both high frequency occurrence of El Niño and La Niña phenomenon and short term switch of PDO events.
\end{abstract}

satellite altimetry, tide gauge, sea level variation, ENSO, PDO

Citation: Jin T Y, Li J C, Jiang W P, et al. Low-frequency sea level variation and its correlation with climate events in the Pacific. Chin Sci Bull, 2012, 57: 3623-3630, doi: 10.1007/s11434-012-5231-y

GMSL variation is mainly estimated by satellite altimeter measurements and tide gauge observations. The significant long-term trend and seasonal signals have been revealed through long term researches [1-3], but it is known little about the low frequency characteristics of inter-annual and decadal variations. According to the 4th report of IPCC [4], the GMSL rise is an indisputable fact, but whether its rate is faster or not, is the problem still need to be studied further. In the past few decades, there appears strong amplitude of sea level rise between the western Pacific and eastern Indian Ocean. The large inter-annual variability is associated with the El Niño events. By using satellite altimeter measurements, there have been a few results about the correlation of sea level variation with El Niño and La Niña events in the Pacific [5-7]. However, the frequency of these two events is not regular, which happens once in approximately every 2-7 years. What is more, there are still much lower fre-

*Corresponding author (email: wpjiang@whu.edu.cn) quency sea level variations, such as the low frequency oscillations in the period of 50-70 year lead by sea surface temperature anomalies in the PDO events, which cannot be estimated by shorter satellite altimeter measurements.

Although the long-endured and stable tide gauges provide nearly 150 years' observations that can be used for the analysis of decadal sea level variations, the tide gauges are sparse in the earlier years and these parts of records only represent the mean sea level variation within the localized area. Therefore, it is difficult to get the time series of GMSL variation, e.g. the rate of sea level variation can be 5 times of the global mean within some sea areas. Multi-satellite altimetry can not only collect the nearly global coverage high resolution sea level observations, but also accurately display sea level variations of different regions, and make up for the shortage of spatial distribution for tide gauges. By combining the advantages of high spatial sampling rate of satellite altimetry and the high temporal sampling rate of tide gauges, it can get more detailed characteristics of sea 
level variation and fully play the strengths of these two kinds of measurements. Based on this idea, this paper will reconstruct the time series of GMSL variation during the period from 1948-2007 by combining altimeter and tide gauge observations, analyze the decadal characteristics and long-term trend of GMSL variation, as well as the correlation of low frequency sea level variation with El Niño, La Niña and PDO events.

\section{Reconstruct the time series of GMSL variation}

A reliable long-term trend of sea level variation can be derived from tide gauge observations, but only limited to the local sea-level variation of the single station observations. Conventionally, the long term trend of GMSL is determined refers to a method through selecting global distributed tide gauges with high quality and long time of observations, determining the long-term trend of sea-level variation for each station after post-glacial rebound (PGR) correction and inverse barometric correction, and then obtaining the results after taking weighted average value of each station. When the distribution of selected tide gauges reaches certain uniformity on the world's oceans, the method can determine a more accurate GMSL trend, but there is still a certain amount of tide gauges that are very unevenly distributed. As most of these unevenly distributed tide gauges are located in the boundary of land and ocean, nothing can be done to obtain the spatial distribution characteristics of sea-level variation or the time series of the GMSL variation neither. Therefore, affected by the variation characteristics of the shore waters where the tide gauges are located, the time series of sea-level variation calculated by directly averaging the global observations with significant limitations in the corresponding time will turn out to be strong seasonal variations. However, due to the high spatial resolution nearly global coverage sea surface height measurements accessed by satellite altimetry, the seasonal signals of GMSL variation determined by global mean sea surface height model or collinear method [8] have been smoothed or weakened to a great extent.

\subsection{The reconstruct principles and methods}

Supposing that the spatial distribution characteristics variation of the sea-level variation is very small over time, then we can establish the time series of gridded GMSL variation by using of nearly global coverage satellite altimeter measurements, and then use the Empirical Orthogonal Function (EOF) for decomposition or singular value decomposition (SVD) method to extract the principal components that can describe the spatial distribution characteristics. After that, according to location within the same grid, the sea-level variations observed by the tide gauges after PGR correction and inverse barometric correction in the same time interval are weighed averaged to be taken as the value of grid. And then, the corresponding time series of gridded GMSL variation can be established as a result. Then, by combining the extracted space distribution characteristics, we can get the temporal variability characteristics of each principal component by inverse solution based on principal component analysis. Finally, we can reconstruct the time series of gridded GMSL variation by using of the spatial distribution characteristics and the solved temporal variability characteristics.

For $m \times n$ matrix $\mathbf{H}$, it can be obtained by SVD $[9,10]$ :

$$
\mathbf{H}=\mathbf{U} \cdot \mathbf{S} \cdot \mathbf{V}^{\mathbf{T}},
$$

where $\mathbf{U}$ is an $m \times n$ orthogonal matrix and its column vector is the eigenvector of $\mathbf{H}$, corresponding to the EOFs describing the spatial distribution; $\mathbf{V}^{\mathbf{T}}$ is an $n \times n$ orthogonal matrix and its row vectors provide the principal components describing the temporal variability of each EOF; $\mathbf{S}$ is an $n \times n$ diagonal matrix and its diagonal values are the eigenvalues of $\mathbf{H}$, which corresponds to the energy of EOFs, namely, the degree of contribution to $\mathbf{H}$. After ranking the diagonal values of $\mathbf{S}$ from largest to smallest, the spatial distribution characteristics represented by the first EOF boast the greatest energy in $\mathbf{H}$, followed by the second, and so on.

The reconstruction methods and steps of the time series of gridded GMSL variation by satellite altimeter measurements and tide gauge observations are shown as follows:

(1) The tide gauges are mainly located in the coast and river estuaries, and the regional sea level variations estimated from which are affected by large seasonal signals. Therefore, we should firstly remove the seasonal signals in the time series of gridded GMSL variation by satellite altimeter measurements. Then the time series will be represented as the three-dimensional matrix $h(x, y, t)$ with plane location $(x, y)$ and time $t$. Lastly, the EOFs $\alpha_{k}(x, y)$ describing the spatial distribution are obtained by SVD:

$$
h(x, y, t)=\sum_{k=1}^{n} \alpha_{k}(x, y) \beta_{k}(t),
$$

where $n$ is the total number of EOFs; $\alpha_{k}(x, y)$ is the $k$ th EOF and the $k$ th column vector of $\mathbf{U}$, describing the $k$ th spatial distribution characteristics of GMSL variation; $\beta_{k}(t)$ is the amplitude corresponding to $k$ th EOF, and refers to the $k$ th row vector of the multiplication of $\mathbf{S}$ and $\mathbf{V}^{\mathrm{T}}$, describing the temporal variability of the $k$ th EOF.

(2) After the PGR correction by model and inverse barometric correction by the atmospheric pressure data on tide gauge observations, the seasonal signals are removed. Then by using of the weighed average at the same time interval by location in the same grid, the time series $T(x, y, t)$ of gridded GMSL variation from tide gauge observations is obtained. Based on the EOFs $\left(\alpha_{k}(x, y), k=1,2 \cdots, n\right)$ obtained above, by choosing the first $l$ modes, the amplitude 
$p_{k}(t)$ corresponding to each EOF is solved by least square in the corresponding time:

$$
v_{t}=\sum_{k=1}^{l} \alpha_{k}(x, y) p_{k}(t)-T(x, y, t),
$$

where $v_{t}$ is the reconstruction error caused by the ignorance of the high degree EOFs.

(3) Then the time series $R(x, y, t)$ of gridded GMSL variation is reconstructed by using of the selected first $l$ EOFs and calculated amplitude $\hat{p}_{k}(t)$ :

$$
R(x, y, t)=\sum_{k=1}^{l} \alpha_{k}(x, y) \hat{p}_{k}(t) .
$$

\subsection{The datasets and processing}

The tide gauge observations are the Revised Local Reference (RLR) tide gauge dataset to the end of 2007 from data archive of the Permanent Service for Mean the Sea Level (PSMSL) [11]. The ICE-5G model [12] is used for the PGR correction, and the NCEP/NCAR reanalysis atmospheric pressure data from 1948 to present is used for inverse barometric correction. From the analysis of RLR dataset, the amount of tide gauge observations had increased since the 1950 s, to the peak in the late 1980s, and then it starts to decrease. The amount of observations in 2007 is basically the same as in the early 1960s. Therefore, considering the integrity and continuity, the tide gauge observations from 1948 to 2007 are selected for reconstruction. After eliminating the repeated and low-quality observations [13,14], 769 tide gauges have been chosen, and its global distribution is shown in Figure 1.

Satellite altimeter measurements are the combined Merged Geophysical Data records of T/P and Jason-1 from January 1993 to December 2007. By reference to the latest data processing methods [15-18], the error correction in the original dataset are subject to the refined treatment as follows: we smooth the dual-frequency ionosphere correction, calibrate the deviation of wet meteorological tropospheric correction, correct the sea state bias model and update the tidal model with GOT4.7, respectively. Then, by combining the T/P and Jason-1 measurements, we establish the time

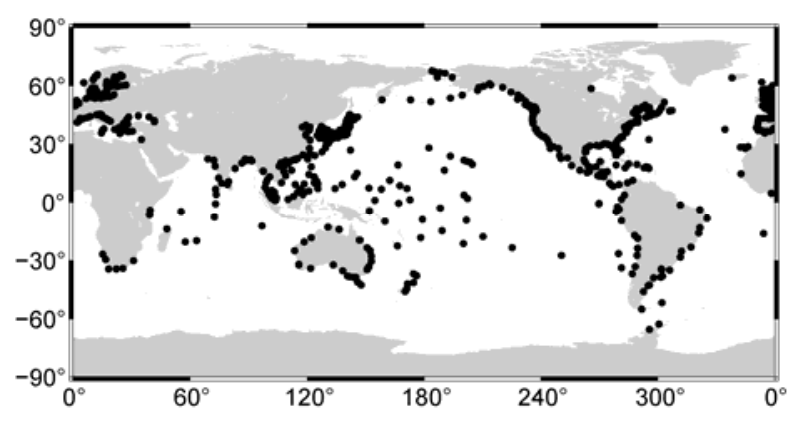

Figure 1 Distribution of selected tide gauges in the reconstruction. series of $1^{\circ} \times 1^{\circ}$ gridded monthly GMSL variation within the range of $\pm 66^{\circ}$ global latitude from 1993 to 2007 . The sealevel variation determined by satellite altimeter measurements is related to the reference ellipsoid, while the one estimated by tide gauge observations is related to land. In order to ensure the consistency of datum, we take 1993.0 as the reference epoch and fit a quadratic on sea-level variations from both to remove the bias, as well as $-0.3 \mathrm{~mm} / \mathrm{a}$ PGR correction on the time series of gridded GMSL variation from satellite altimetry [19].

\subsection{The time series reconstruction}

Based on the time series of gridded GMSL variation, we extract the EOFs by SVD. Through the analysis on the amount of first 70 EOFs from highest to lowest and the amount of accumulated energy, the first EOF describing the long-term trend accounts for $45.4 \%$, the amount of cumulative energy of the first 20 EOFs accounting for nearly $85 \%$, and more than $90 \%$ to 40 EOFs. When the number continues to increase, the cumulative increase in energy has been very slow, i.e. 95 percent to about 70 EOFs.

To select the EOFs involved in the reconstruction, when the number equals $5,10,20,30,40,50$, and 60, we compare the time series of monthly GMSL variation from 1993 to 2007 by reconstruction with that determined from satellite altimeter measurements. Figure 2 shows the mean and RMS of their difference. When the number of EOFs varies from 5 to 40 , the mean value declines. When the number is greater than 40 , the mean value starts to increase. The RMS decreases from 5 to 50 in turn; when it is greater than 50 , it begins to increase.

Overall, the number of EOFs should be between 30 and 40 in reconstruction, while the increase of mode number will lead to a substantial increase in computation. Therefore, the first 30 EOFs are selected to carry out the further comparison and validation on the time series of GMSL variation by reconstruction. Figure 3 shows the global spatial distribution of correlation with the results determined by satellite altimeter measurements. From which, we can see a strong correlation at the vicinity of the equatorial Pacific, the east coast of the North Pacific and the North Atlantic where

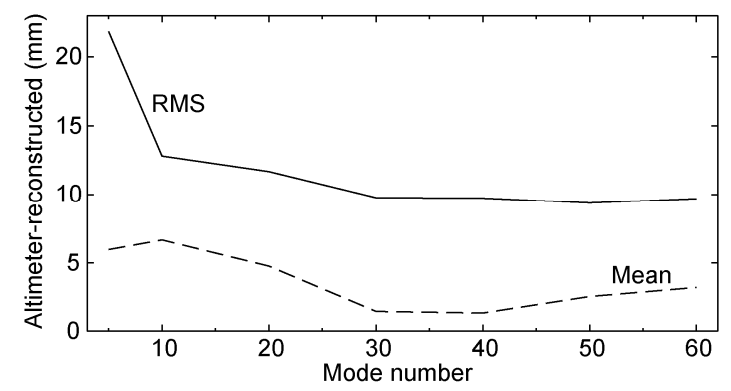

Figure 2 The mean and RMS of difference between the reconstructed time series of monthly GMSL variation and that of satellite altimetry in different EOFs. 


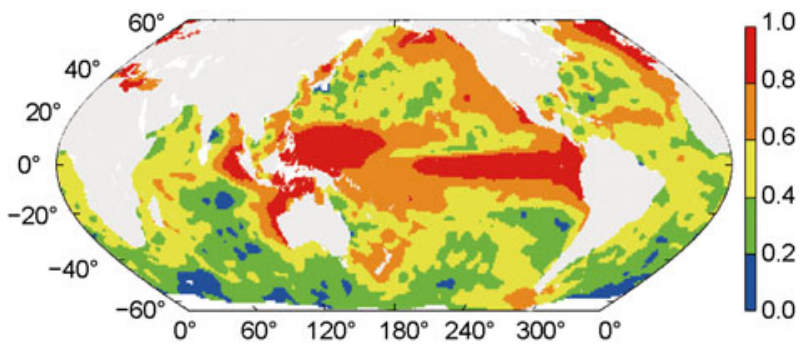

Figure 3 Correlation between the time series of gridded GMSL variation by reconstruction and satellite altimeter measurements during 1993-2007.

intensive tide gauges are located. However, the correlation becomes weak in the Southern Hemisphere as a whole, mainly due to the spare tide gauges, especially in the open ocean. Through statistics, the mean correlation in the worldwide is 0.51 , while 0.61 in the Northern Hemisphere, and 0.44 in the Southern Hemisphere. The mean correlation in Tropical Pacific is 0.77, which shows a strong El Niño characteristic. That is to say, the EOFs describe the lowfrequency sea level variations well.

The spatial distribution of long-term trend extracted from reconstructed time series agrees well with that from satellite altimeter measurements. As shown in Figure 4, Figure 5(a) shows the result of satellite altimeter measurements, and Figure 5(b) shows the result of reconstruction. The highest similarity is found in the North Pacific, the vicinity of the equatorial Pacific and the North Atlantic. However, it is weak in the Indian Ocean, because there are only few tide gauges in the open ocean and the southern tip of Africa, and almost no tide gauge in the Arabian Sea and southern Indian Ocean. In addition, because of extremely rare tide gauges, there is larger deviation in the boundary region of the Southern Pacific where close to the Antarctic. The correlation of the long term trend from both is 0.69 by weighted

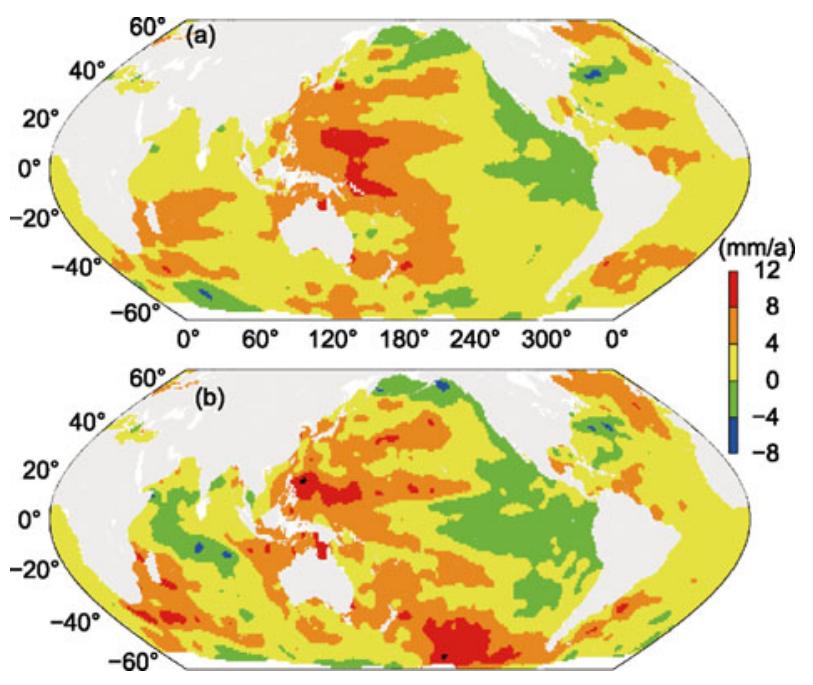

Figure 4 The spatial distribution of long-term trend of GMSL variations by satellite altimeter measurements (a) and reconstruction (b) during 1993-2007.

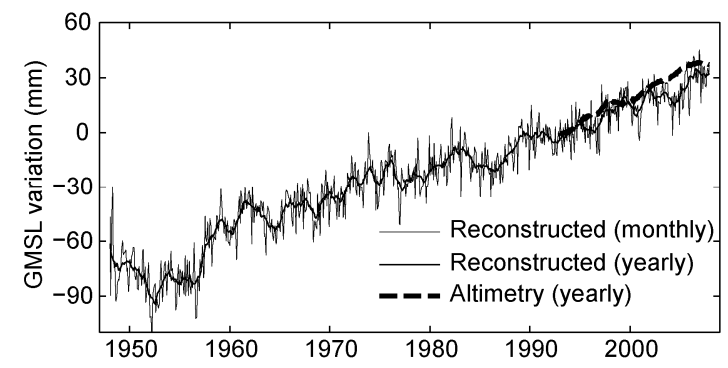

Figure 5 The reconstructed time series of GMSL variation from 1948 to 2007.

average globally and 0.83 by considering only the Northern Hemisphere. The long-term trend of GMSL variation by reconstruction is $2.86 \pm 0.15 \mathrm{~mm} / \mathrm{a}$ from 1993 to 2007 , while the result is $3.05 \pm 0.05 \mathrm{~mm} / \mathrm{a}$ determined from satellite altimeter measurements in the same period, which means that there are in good consistency within the error estimates.

Then, we reconstruct the time series of gridded monthly GMSL variation from 1948 to 2007. And the time series of GMSL variation is achieved by weighed average globally, as shown in Figure 5. Meanwhile, the time series of GMSL variation from 1993 to 2007 by satellite altimeter measurements is also given, which shows good consistency with that of reconstruction. The long-term trend of GMSL variation from 1948 to 2007 is $1.82 \pm 0.02 \mathrm{~mm} / \mathrm{a}$, which agrees with the long-term trend of $1.7 \mathrm{~mm} / \mathrm{a}$ in 20th century given by Douglas [20], and the long-term trend of $1.8 \mathrm{~mm} / \mathrm{a}$ from 1950 to 2000 given by Church et al. [10].

\section{Detection of low-frequency sea-level variation}

The long term trend of GMSL variation is about 1-2 mm/a in 20th century [4]. While the trend estimated by satellite altimeter measurements from 1993 to 2003 is approximately $3.1 \mathrm{~mm} / \mathrm{a}$ [21-23], which is significantly higher than that of the 20th century, thus leaving a conclusion that the rate of sea-level rise may be accelerating. However, the conclusion is drawn by only considering the long-term trend and the characteristics of seasonal signals, while ignoring the longer cycle of low-frequency variation that may exist. From the time series of GMSL variation in the reconstruction, the decadal characteristics can be seen (Figure 5). So we calculate the time series of decadal linear trends between 1952 and 2002 for overlapping 10 year periods. Also, by using of ocean temperature and salinity data [24], we calculate the time series of global average steric sea level variations from 1945 to 2006 [25], and from which, the time series of decadal linear trends between 1949 and 2001 is estimated. As shown in Figure 6, the decadal linear trends of GMSL variation and steric sea level variation have both obvious characteristics in nearly 10-year cycle, and their phases are also in good consistency.

Through statistics of the annual tide gauge observations, 


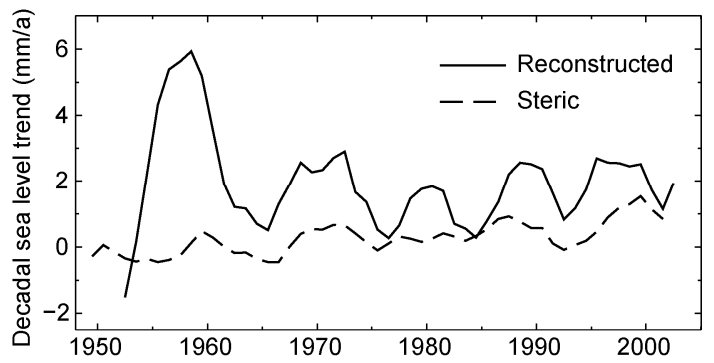

Figure 6 The decadal linear trends of GMSL variation by reconstruction and steric sea level variation calculated by Ishii's temperature and salinity data.

the annual total number has rapidly increased in the 19481958 period from 2181 to 4021 . It can be seen from Figure 5 that the reconstructed GMSL variation has stabilized in the late 1950s. But for the decadal linear trend, the results in the early 1960s will be affected by the reconstructed GMSL variations of the late $1950 \mathrm{~s}$. So certain anomalies exist in the decadal linear trends of early 1960s as shown in Figure 6. Ray and Douglas [26] also pointed out that the sparse tide gauge data had made the reconstructed sea level variations very sensitive before 1950 . Except for this period, after fitting a quadratic with linear trend and decadal cycle, the acceleration of GMSL rise from 1963 to 2002 is $0.010 \pm 0.009$ $\mathrm{mm} / \mathrm{a}^{2}$, while that of global average steric sea level rise is
$0.023 \pm 0.004 \mathrm{~mm} / \mathrm{a}^{2}$ from 1963 to 2001 , indicating that the rate of sea level rise accelerates in the latter half of the 20th century. This result agrees with the GMSL variation acceleration of $0.008 \mathrm{~mm} / \mathrm{a}^{2}$ in the 20th century calculated by Church [27], as well as with the steric sea level rise acceleration of $0.005 \pm 0.003-0.014 \pm 0.004 \mathrm{~mm} / \mathrm{a}^{2}$ from 1910 to 1990 in the 3rd report of IPCC estimated by the climate models [28].

\section{Analysis on low-frequency GMSL variation signal}

El Niño, La Niña and PDO events will cause low-frequency inter-annual or decadal sea-level variation. Firstly, we remove the bias, linear trend and seasonal signals from the time series of 15-year gridded GMSL variation by satellite altimeter measurements. Then, through the analysis of EOFs, the strong El Niño characteristics can be seen from the spatial distribution of GMSL variation, indicating that the remaining sea level variation are mainly represented by low-frequency signals. As shown in Figure 7, we can see the first two EOFs show significant El Niño and La Niña characteristics.

On the basis of time series of gridded GMSL variation after removing the bias, linear trend and seasonal signals,
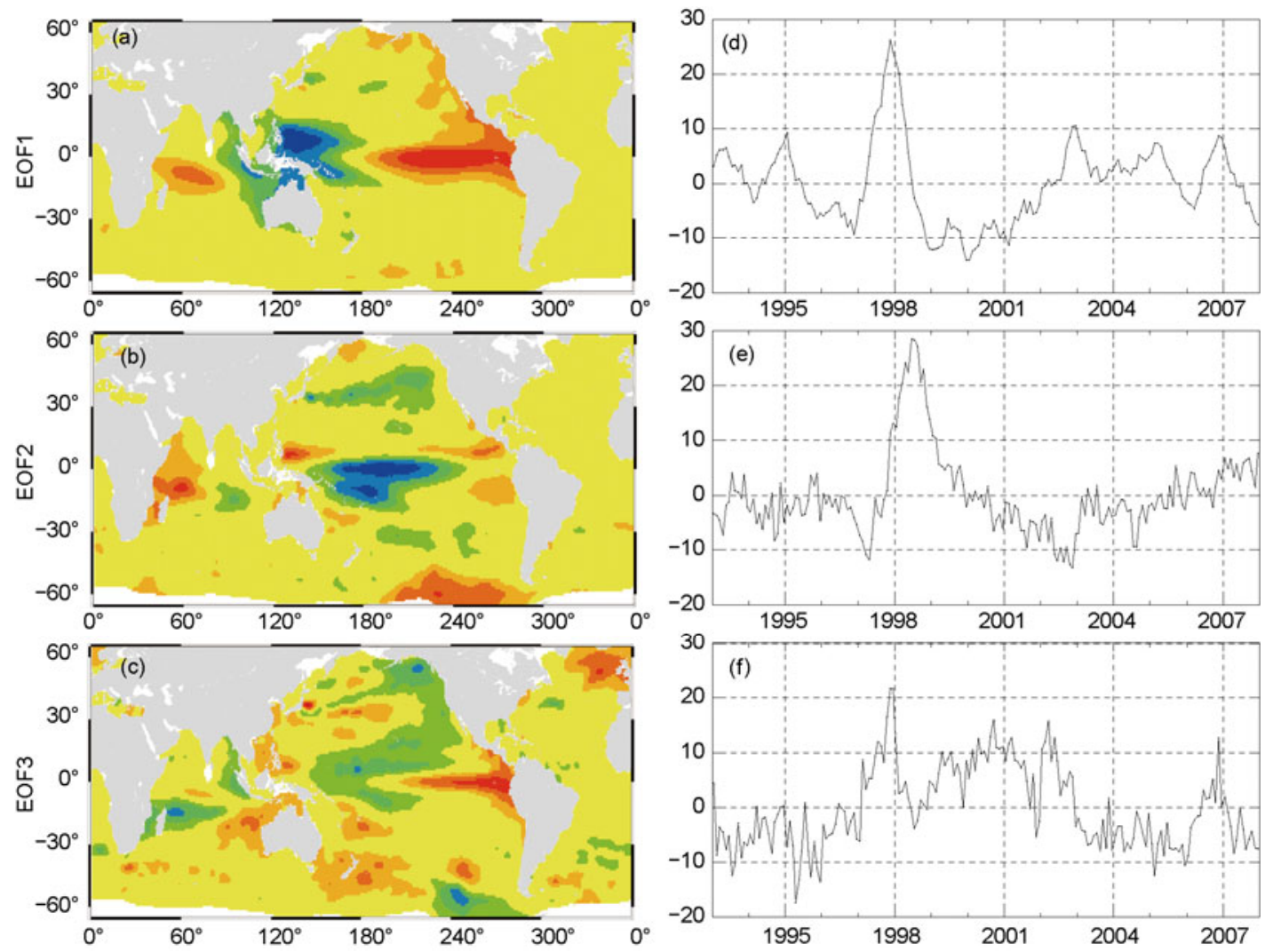

Figure 7 The first three EOFs of the time series of gridded GMSL variation by satellite altimeter measurements after removal of the linear trend and seasonal signals. (a)-(c) The spatial distribution characteristics; (d)-(f) the corresponding temporal variability characteristics. 
and by selecting the first 20 EOFs, the time series of low-frequency GMSL variation from 1948 to 2007 is estimated. As shown in Figure 8, it can be seen that the time series is mainly represented as long-period low frequency sea level variation signals.

\subsection{Correlation analysis with ENSO}

ENSO is one of the most important events affecting the inter-annual global climate change, the influence of which is mainly measured by the Southern Oscillation Index (SOI) [29]. We select the SOI time series provided by U.S. National Center for Atmospheric Research (NCAR) in this paper. When the air pressure over the equatorial Pacific is lower at the east while higher at the west compared to the normal, the SOI value decreases to negative, and at the same time, sea surface temperature is lower at the west and higher at the east, which means the occurrence of El Niño. On the contrary, when the SOI value increases to positive, it means the occurrence of La Niña, as shown in Figure 9(a). For the periods from 1982 to 1983 and from 1997 to 1998, a very small SOI exists and El Niño event occurs. The time series of low frequency GMSL variation by reconstruction and SOI are normalized and processed with one-year moving average to remove the residual seasonal signals, so as to ensure the remaining part mainly reflects the inter-annual GMSL variation signals. Then these two time series are compared, as shown in Figure 9(b), in which the SOI is multiplied by -1 so that it is positive when El Niño occurs.

It can be seen that their trends are basically the same, but still some differences exist in several years. When the absolute value of SOI is relatively larger, which means the occurrence of El Niño or La Niña, the GMSL variation has a great extent change. The two largest differences occurred in the period of 1957-1966 and 1990-1996. Among which, there are three El Niño and three La Niña events between 1957 and 1966, and three El Niño and one La Niña events between 1990 and 1996. Especially, there are three consecutive El Niño events from 1991 to 1995 . The high frequency of extreme events causes continuous anomalies in sea level, weakening the correlation between the time series of GMSL variation and SOI. For the three more independent

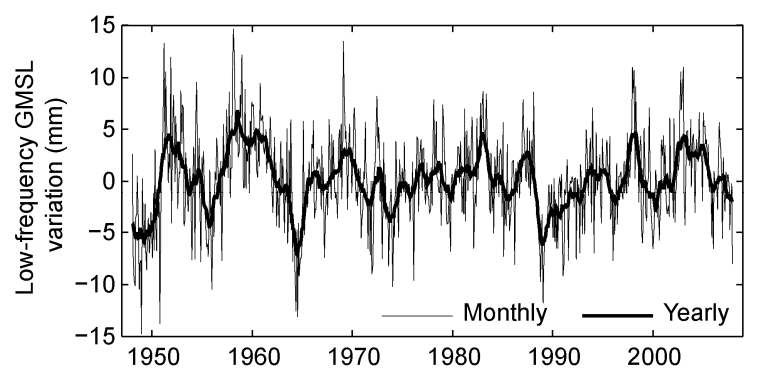

Figure 8 The reconstructed time series of low-frequency GMSL variation from 1948 to 2007.

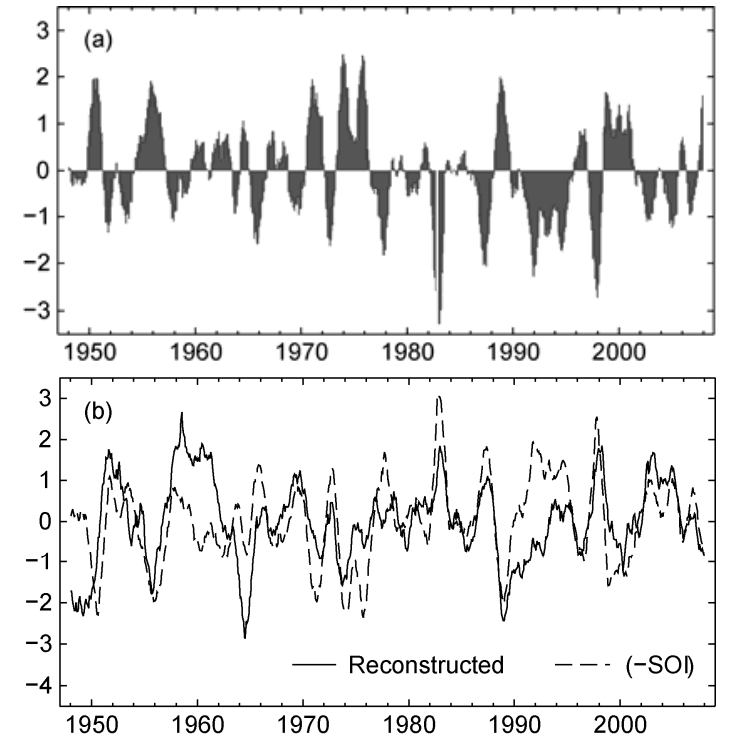

Figure 9 The time series of SOI from 1948 to 2007(a) and its correlation with the reconstructed low-frequency GMSL variation after normalization and one year moving average (b).

and stronger El Niño events in the period of 1982-1983, 1986-1987 and 1997-1998, respectively, the GMSL variation shows a high correlation with SOI. For the five stronger La Niña events occurred in the period of 1951-1952, 19541957, 1975-1977, 1988-1989 and 1998-2000, it also shows a high correlation.

\subsection{Correlation analysis with PDO}

PDO is an El Niño-like longer-term climate event in the Pacific. Its main focus area occurs near the North Pacific and North American continent, and the secondary focus area occurs in the tropical Pacific, the duration of which could reach 20 to 30 years. It has been found that the PDO event is in "cold phase" from 1948 to 1976, and "warm phase" in the period from 1977 to the late 1990s, among which there exists a short-term of inverting phase of the cold and warm. According to the time series of temperature anomaly in the Pacific at north of $20^{\circ} \mathrm{N}$ after the removal of global average sea temperature anomalies, the first principal component is extracted and defined as the PDO index [30]. We select the time series of monthly average PDO index proposed by Atmosphere and Ocean Joint Institute of the University of Washington, as shown in Figure 10(a), i.e. when it is greater than 0 , it means the "warm phase"; when it is less than 0 , it means the "cold phase".

The time series of reconstructed low frequency GMSL variation and PDO index are normalized and processed with two-year moving average to remove the residual seasonal and major inter-annual signals, and then there are compared, as shown in Figure 10(b). It can be seen that the trends of them are roughly the same, but these exists a certain difference in several periods. Among which, the greatest difference 

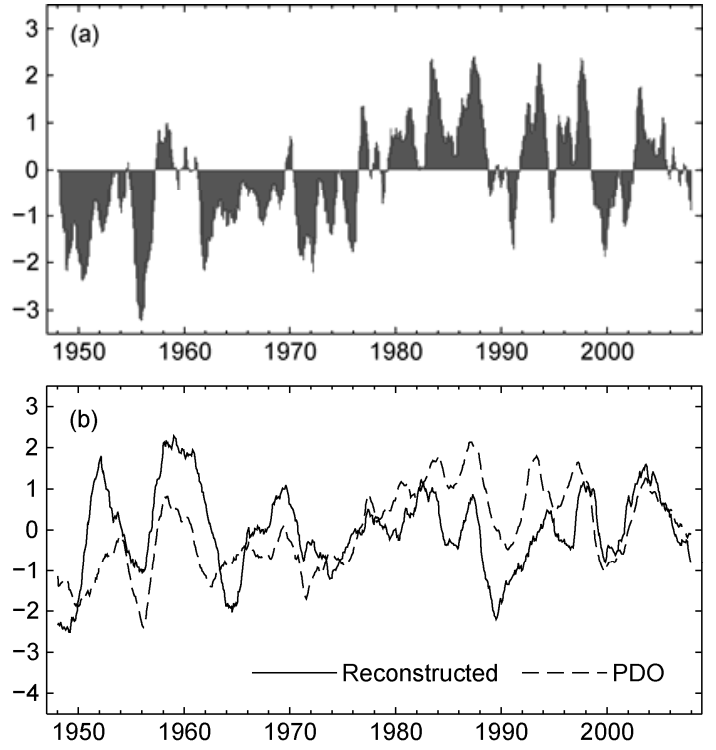

Figure 10 The time series of PDO index from 1948 to 2007 (a) and its correlation with the reconstructed low-frequency GMSL variation after normalization and two-year moving average (b).

is located at the period when the PDO short-term anti-phase index exists, i.e. warm index in the cold phase during the period of 1959-1961 and 1969, and cold index in the warm phase during the period of 1989-1991. At the same time, the maximum difference between low frequency GMSL variation and SOI occurs. Therefore, the reasons for large difference may due to the result of both the high frequency El Niño, La Niña and PDO events. In addition, there may be other longer period characteristic of sea level variations, and sparse tide gauges in the open ocean of Pacific may also exert an impact.

\section{Conclusion}

In this paper, we make joint use of the global distribution of satellite altimeter measurements and long time span of tide gauge observations to reconstruct long time series of GMSL variation with a uniform spatial distribution. Based on the time series of reconstructed GMSL variation and steric sealevel variation calculated by ocean temperature and salinity data, the characteristic of decadal and other long period variation of both are found. In addition, the rate of GMSL rise is confirmed to be accelerating in the latter half of the 20th century, and the GMSL rise during the period of 1993-2003 is situated in an acceleration period of the lowfrequency oscillation. Based on the correlation analysis of time series of low-frequency GMSL variation with SOI and PDO index, we can see that sea level variation can reveal several abnormal climate events. The results can provide the necessary information and scientific basis for the responses to global climate change.
This work was supported by the National Key Basic Research Program of China (2012CB957703), the National Natural Science Foundation of China (41004007, 41074014) and China Postdoctoral Science Foundation (2011M500886).

$1 \mathrm{Hu}$ J G, Li J C, Dong X J, et al. Using satellite altimetry technique for monitoring the sea level change (in Chinese). Acta Geod Cart Sin, 2001, 30: 316-321

2 Wen H J, Zhang C Y. EOF Analysis of sea level anomaly time series derived from ERS-2 and TOPEX altimeter data (in Chinese). Geomat Inf Sci Wuhan Univ, 2006, 31: 221-223

3 Zhan J G, Wang Y, Xu H Z, et al. The wavelet analysis of sea level change in China Sea during 1992-2006 (in Chinese). Acta Geod Cart Sin, 2008, 37: 438-443

4 Bindoff N L, Willebrand J, Artale V, et al. Observations: Oceanic climate change and sea level. In: Solomon S, Qin D, Manning M, et al. eds. Climate Change 2007: The Physical Science Basis. Contribution of Working Group 1 to the Fourth Assessment Report of the Intergovernmental Panel on Climate Change. New York: Cambridge University Press, 2007. 385-432

5 Wang Z T, Li J C, Chao D B, et al. Correlativity study between ENSO phenomenon and mean sea level abnormal variations in equator Pacific area using Satellite Altimetry (in Chinese). Geomat Inf Sci Wuhan Univ, 2004, 29: 699-703

6 Liu X Y, Liu Y G, Guo L, et al. Change of mean sea level of lowfrequency on east China Sea and its relation with ENSO (in Chinese). J Geod Geodyn, 2009, 29: 55-63

7 Gu X L, Li P L. Pacific sea level variations and its factors (in Chinese). Acta Oceanol Sin, 2009, 31: 28-36

8 Jiang W P, Li J C, Wang Z T. Determination of global mean sea surface WHU2000 using multi-satellite altimet-ric data. Chin Sci Bull, 2002, 47: 1664-1668

9 Chambers D P, Mehlhaff C A, Urban T J, et al. Low-frequency variations in global mean sea level: 1950-2000. J Geophys Res, 2002, 107: 3026

10 Church J A, White N J, Coleman R, et al. Estimates of the regional distribution of sea level rise over the 1950-2000 period. J Clim, 2004, 17: 2609-2625

11 Woodworth P L, Player R. The permanent service for mean sea level: An update to the 21st century. J Coast Res, 2003, 19: 287-295

12 Peltier W R. Global glacial isostasy and the surface of the ice-age Earth: the ICE-5G (VM2) model and GRACE. Annu Rev Earth Planet Sci, 2004, 32: 111-149

13 Douglas B C. Global sea rise: A redetermination. Surv Geophys, 1997, 18: 279-292

14 Kuo C Y. Determination and Characterization of 20th Century Global Sea Level Rise. The OSU Report No. 478, 2006

15 Blanc F, Borra M, Boudou P. AVISO User Handbook for Merged TOPEX/POSEIDON Products, Version 3.0. 1996

16 Callahan P. TOPEX GDR Correction/Jason Compatibility Product Users Guide. 2002

17 Chambers D P, Hayes S A, Ries J C, et al. New TOPEX sea state bias models and their effect on global mean sea level. J Geophys Res, 2003, 108: 3305

18 Ray R D, Lyard F, Roblou L. Thoughts on Shallow-Water Tides \& Altimetry. In: CIOSS/NOAA Coastal Altimeter Workshop, Maryland, 2008: 21-23

19 Douglas B C, Peltier W. The puzzle of global sea-level rise. Phys Today, 2002, 55: 35-41

20 Douglas B C. Sea level change in the era of the recording tide gauge. In: Douglas B C, Kearney M S, Leatherman S P, eds. Sea Level RIse: History and Consequences. New York: Academic Press, 2001. 3764

21 Cazenave A, Nerem R S. Present-day sea level change: Observations and causes. Rev Geophys, 2004, 42: RG3001

22 Leuliette E W, Nerem R S, Mitchum G T. Calibration of TOPEX/ Poseidon and Jason altimeter data to construct a continuous record of mean sea level change. Mar Geod, 2004, 27: 79-94 
23 Nerem R S, Leuliette E W, Cazenave A. Present-day sea-level change: A review. C R Géosci, 2006, 338: 1077-1083

24 Ishii M, Kimoto M. Reevaluation of historical ocean heat content variations with time-varying XBT and MBT depth bias corrections. J Oceanogr, 2009, 65: 287-299

25 Jin $\mathrm{T} \mathrm{Y}$, Li J C, Wang Z T, et al. Global ocean mass variation in recent four years and its spatial and temporal characteristics. Chin $\mathrm{J}$ Geophys, 2010, 53: 26-34

26 Ray R D, Douglas B C. Experiments in reconstructing twentiethcentury sea levels. Prog Oceanogr, 2011, 91: 496-515

27 Church J A, White N J. A 20th century acceleration in global sea-level rise. Geophys Res Lett, 2006, 33: L01602

28 Church J A, Gregory J M, Huybrechts P, et al. Changes in sea level. In: Houghton J T, Ding Y, Griggs D J, et al. eds. Climate Change 2001: The Scientific Basis: Contribution of Working Group I to the Third Assessment Report of the Intergovernmental Panel on Climate Change. New York: Cambridge University Press, 2001. 639-694

29 Trenberth K E. Signal versus noise in the Southern Oscillation. Mon Weather Rev, 1984, 112: 326-332

30 Mantua N J, Hare S R, Zhang Y, et al. A Pacific interdecadal climate oscillation with impacts on salmon production. Bull Amer Meteor Soc, 1997, 78: 1069-1079

Open Access This article is distributed under the terms of the Creative Commons Attribution License which permits any use, distribution, and reproduction in any medium, provided the original author(s) and source are credited. 